\title{
A Robust Estimation of the CAPM with a Heavy-tailed Distribution
}

\author{
Chikashi Tsuji ${ }^{1}$ \\ ${ }^{1}$ Faculty of Economics, Chuo University, Tokyo, Japan \\ Correspondence: Chikashi Tsuji, Professor, Faculty of Economics, Chuo University, 742-1 Higashinakano, Hachioji-shi, \\ Tokyo 192-0393, Japan.
}

Received: March 14, 2017

Accepted: April 15, 2017

Available online: April 18, 2017

doi:10.11114/ijsss.v5i5.2362

URL: https://doi.org/10.11114/ijsss.v5i5.2362

\begin{abstract}
This study quantitatively explores the linear standard capital asset pricing model (CAPM) and a non-linear CAPM by using ten US representative firms' monthly stock returns. By the maximum likelihood estimation, we derive the following useful findings. (1) First, when the stock return distribution is fat-tailed, our non-linear CAPM application is highly effective. Because our non-linear CAPM parameters very well capture the behavior of fat-tailed returns, the non-linear CAPM estimation derives more reliable beta value estimates than the standard linear CAPM. (2) Second, conducting the Wald tests based on both the standard linear CAPM and non-linear CAPM estimators, we clarify that when the stock return distribution is fat-tailed, the Wald test result based on the non-linear CAPM estimators is more reliable than that based on the standard linear CAPM estimators.
\end{abstract}

Keywords: fat-tail, non-linear CAPM, Student's $t$-distribution, US stock market, Wald test

\section{Introduction}

Asset pricing is a significant research field since it helps investors to understand not only pricing mechanisms of financial assets but also their investments' risk and return relationship. In order to enable investors to make more effective and reasonable investment decisions, a robust asset pricing model is therefore needed. The capital asset pricing model (CAPM) is one of the most famous asset pricing models (Sharpe, 1964; Lintner, 1965; Mossin, 1966); and this model has been heavily used as a standard model for examining stock returns. In many academic studies and practical applications of this model, the standard linear regression approach has been normally employed. In fact, however, stock returns in the real world often have fatter-tailed distributions rather than normal distributions; therefore, more careful applications of the CAPM by incorporating fat-tailed return distributions are required. Based on this argument, this study empirically explores a non-linear CAPM by using monthly stock returns of ten US representative firms.

Our maximum likelihood (ML) estimations in this paper derive the following useful findings. (1) First, when the stock return distribution is fat-tailed, our non-linear CAPM application is highly successful. Because our non-linear CAPM parameters rather effectively capture the behavior of fat-tailed return distributions, the non-linear CAPM estimation derives more reliable beta value estimates than the standard linear CAPM. In our present study, this effectiveness is particularly seen in the cases of the stock returns of Bank of America and Amazon.com. (2) Second, conducting the Wald tests based on the standard linear CAPM and non-linear CAPM estimators, we clarify that when the stock return distribution is fat-tailed, the Wald test result based on the non-linear CAPM estimators is more reliable than that based on the standard linear CAPM estimators. This is seen particularly in the case of the stock return of Bank of America in this study. Furthermore, we consider that when the stock return is normally distributed, our non-linear CAPM estimator-based Wald test is also reliable since the model's degrees of freedom (DOF) parameter can be adjusted for the normal distribution by taking larger DOF values. The above interesting findings for academics and practice are the contributions of this research.

As to the rest of this paper, recent related studies are reviewed in Section 2; our data and variables are explained in Section 3; and in Section 4, our models and quantitative methodology are described. After these, Section 5 explains the results of our analyses and Section 6 concludes the paper.

\section{Literature Review}

This section briefly reviews recent literature related to the CAPM. Tsai et al. (2014) investigated the CAPM betas and downside betas using the wide samples from 23 international stock markets. Although it is pointed out that 
cross-sectional tests of the CAPM are problematic, a study by Guermat (2014) presented that the CAPM was indeed testable by the two-step procedure suggested by this study. However, the objective and methodology of this paper are different from our current study. An interesting study by Barberis et al. (2015) developed a model, where some investors form beliefs as to future stock price changes, while other investors keep fully rational beliefs.

Using Korean stock market data, Hur and Chung (2017) derived the CAPM betas under the incomplete market setting, and they compared these betas with the traditional CAPM betas. Agnello (2016) examined whether the US paintings follow the CAPM, and by the cross sectional tests, this study suggested that little support was obtained for the CAPM, although this study found the evidence that high priced US paintings somewhat supported the CAPM pricing.

Further, Tsuji (2012a) quantitatively examined the alphas of the Japanese equity portfolios while comparing similar US stock portfolios; and he found positive alphas from some Japanese portfolios. Using the US data, Tsuji (2012b) quantitatively investigated the relations of the industry portfolio returns and Fama and French's (1993) three factor returns; however, the study did not employ non-linear estimations of asset pricing models. In addition, there are such related interesting studies as Tiku et al. (1999) and Bai et al. (2010, 2011); however, based on this recent literature review, we consider that a non-linear CAPM estimation conducted as in our present study is rare and much precious.

\section{Data and Variables}

In this section, we describe the data for our research. All monthly stock price data of US firms are from Thomson Reuters. In addition, monthly data of the US excess stock market percentage return and US risk-free percentage rate are from Kenneth French. Subtracting the US risk-free rate from the returns of US firms, we derive their monthly excess returns. More specifically, we compute monthly excess percentage returns of ten US representative firms of Apple Inc., Bank of America Corporation, The Coca-Cola Company, Microsoft Corporation, Wal-Mart Stores, Inc., Amazon.com, Inc., Exxon Mobil Corporation, JPMorgan Chase \& Co., Johnson \& Johnson Services, Inc., and General Electric Company. Hence, this study uses the above 11 excess percentage stock returns in total. The analyzing sample period of this study is from June 1997 to January 2017.

Table 1. Descriptive statistics for the excess returns of the overall US stock market and the US representative firms: For the period from June 1997 to January 2017

\begin{tabular}{lllll}
\hline & Market & Apple & Bank of America & Coca-Cola \\
\hline Mean & 0.5418 & 2.9835 & 0.4339 & 0.0926 \\
Median & 1.1750 & 3.1546 & 0.2639 & 0.2369 \\
Standard deviation & 4.5523 & 12.9140 & 11.7918 & 5.9753 \\
Skewness & -0.6729 & -0.4004 & 0.4046 & -0.2641 \\
Kurtosis & 4.0041 & 5.2509 & 10.9158 & 4.7215 \\
\hline JB stat. & $27.7219^{* * *}$ & $56.1270^{* * *}$ & $622.5971^{* * *}$ & $31.8830^{* * *}$ \\
$p$-value & 0.0000 & 0.0000 & 0.0000 & 0.0000 \\
\hline & Microsoft & Wal-Mart & Amazon.com & Exxon \\
\hline Mean & 0.8629 & 0.6627 & 4.0067 & 0.3967 \\
Median & 1.1607 & 0.3862 & 2.2889 & 0.0238 \\
Standard deviation & 9.3303 & 6.3036 & 18.5556 & 5.0173 \\
Skewness & 0.4431 & 0.3330 & 1.8927 & 0.4148 \\
Kurtosis & 5.1949 & 4.6197 & 12.4679 & 4.3619 \\
\hline JB stat. & $55.0973^{* * *}$ & $30.1608^{* * *}$ & $1022.380^{* * *}$ & $25.0054^{* * *}$ \\
$p$-value & 0.0000 & 0.0000 & 0.0000 & 0.0000 \\
\hline & JPMorgan & Johnson \& Johnson & GE \\
\hline Mean & 0.7062 & 0.5252 & & 0.2940 \\
Median & 0.7870 & 0.4903 & & -0.1303 \\
Standard deviation & 9.4782 & 5.1084 & & 7.6720 \\
Skewness & -0.1888 & -0.1031 & & -0.1575 \\
Kurtosis & 4.1436 & 4.0314 & & 4.4478 \\
\hline JB stat. & $14.2606^{* * *}$ & $10.8792^{* * * *}$ & & 0.0000 \\
$p$-value & 0.0000 & 0.0043 & & \\
\hline
\end{tabular}

Notes: $* * *$ denotes the statistical significance at the $1 \%$ level. Further, JB stat. indicates the Jarque-Bera statistic. The number of our observations is 236 . 


\section{Panel A. Apple}

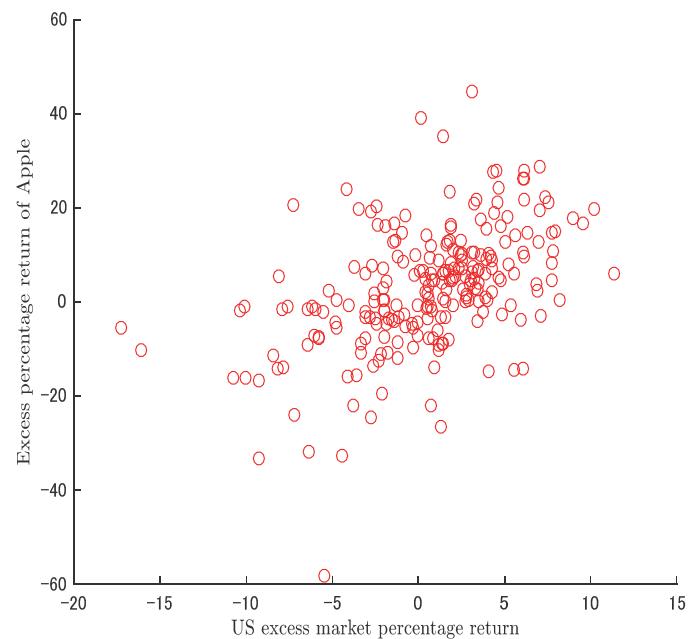

\section{Panel C. Coca-Cola}

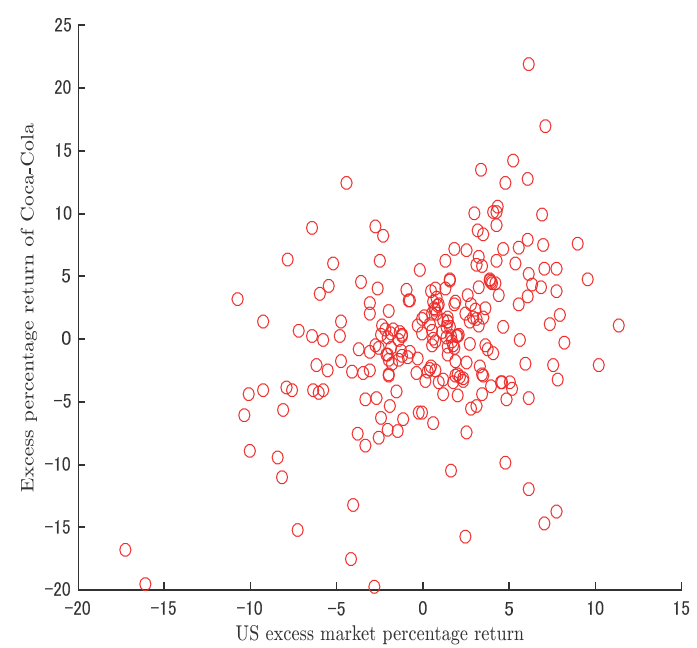

Panel E. Wal-Mart

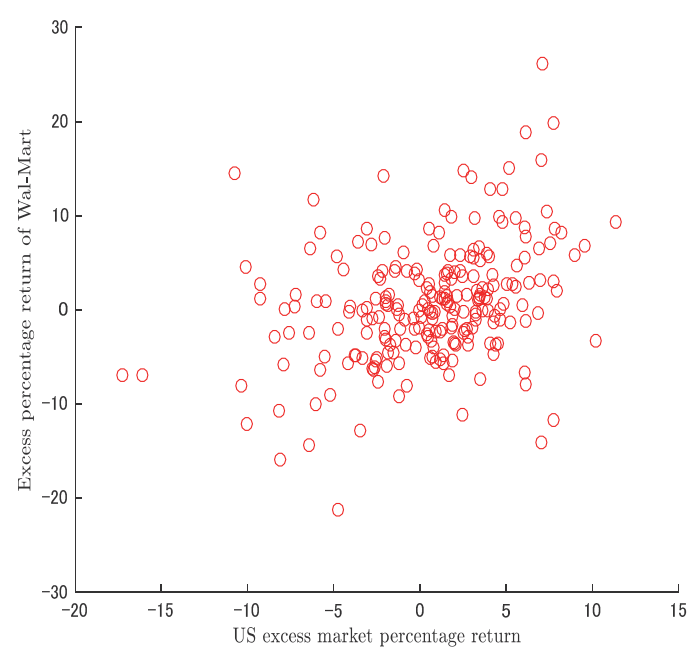

Panel B. Bank of America

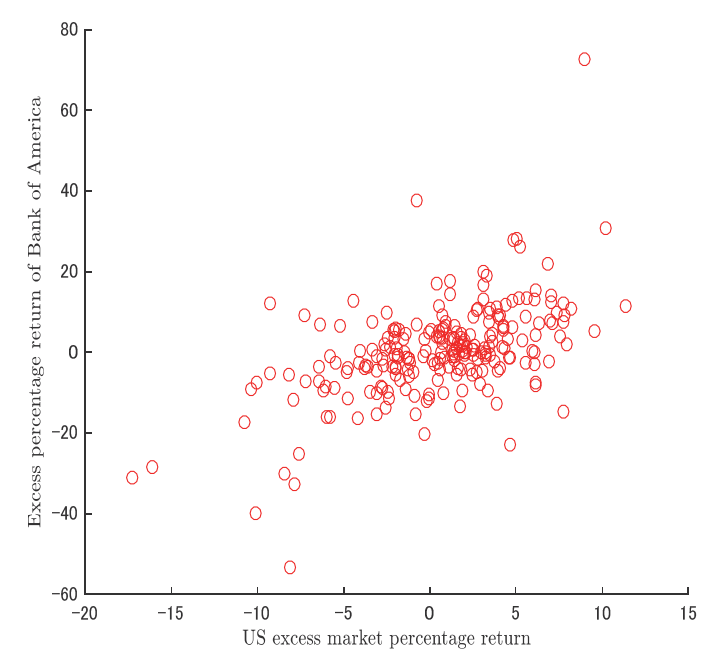

Panel D. Microsoft

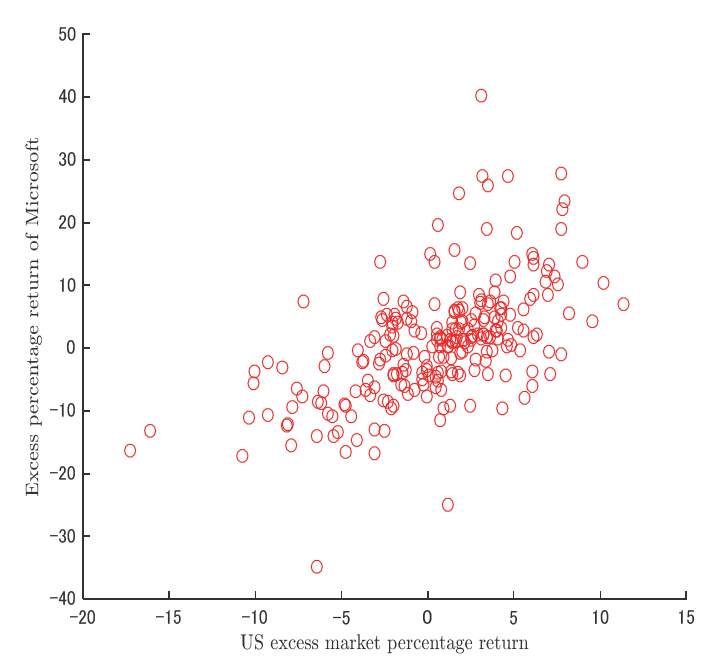

Panel F. Amazon.com

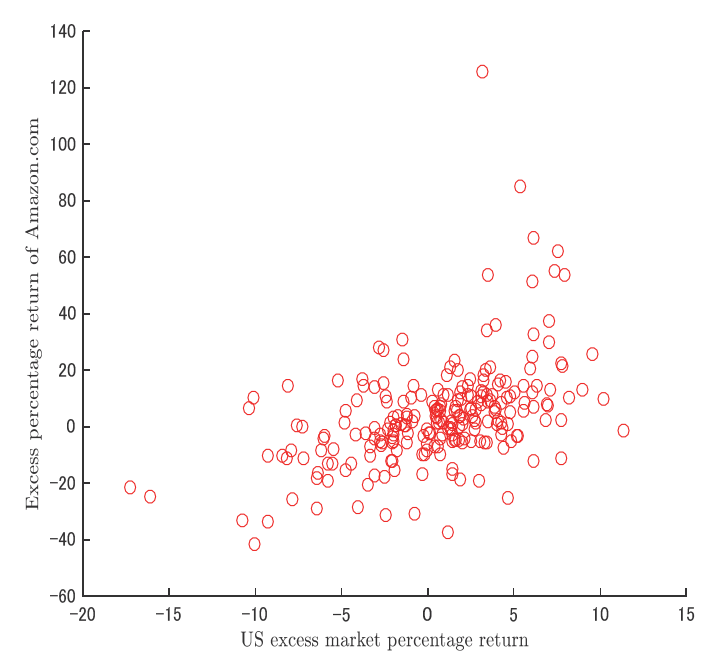


Panel G. Exxon Mobil

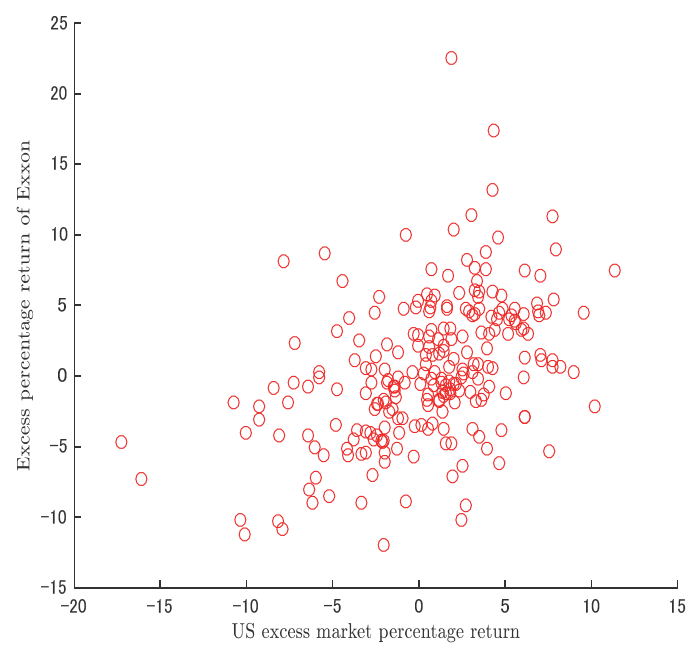

Panel I. Johnson \& Johnson

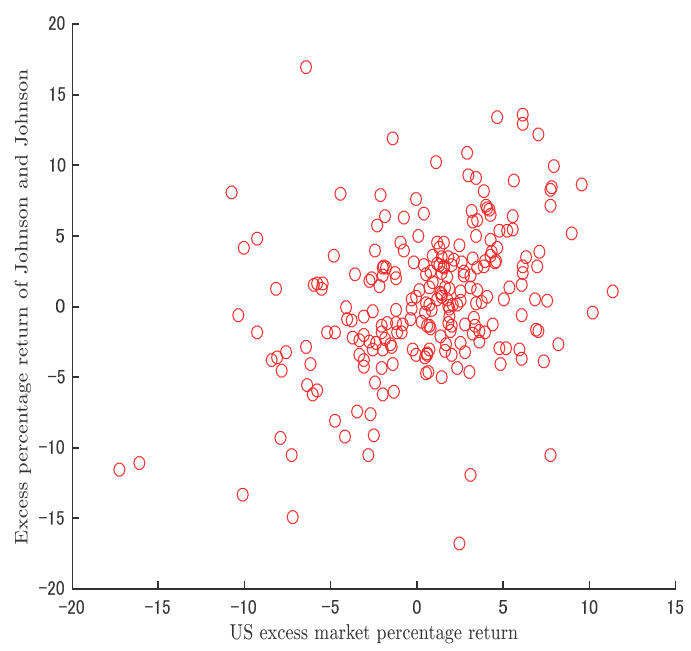

Panel H. JPMorgan

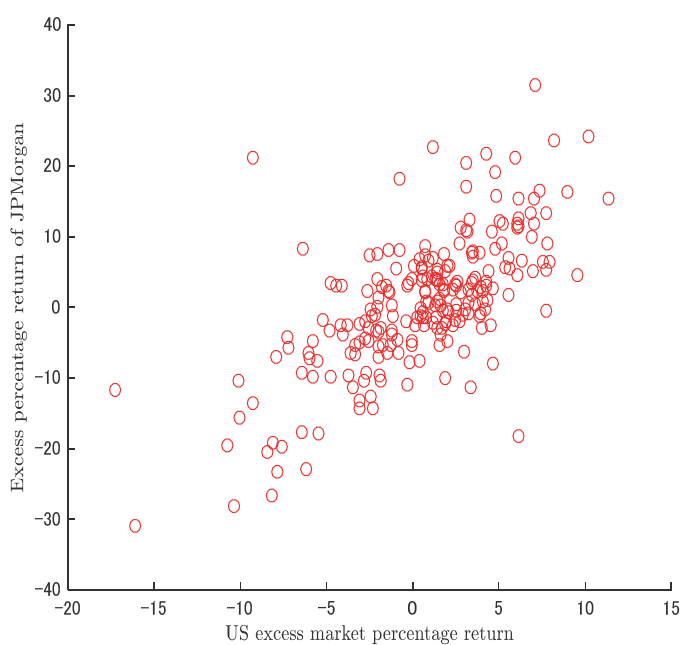

Panel J. GE

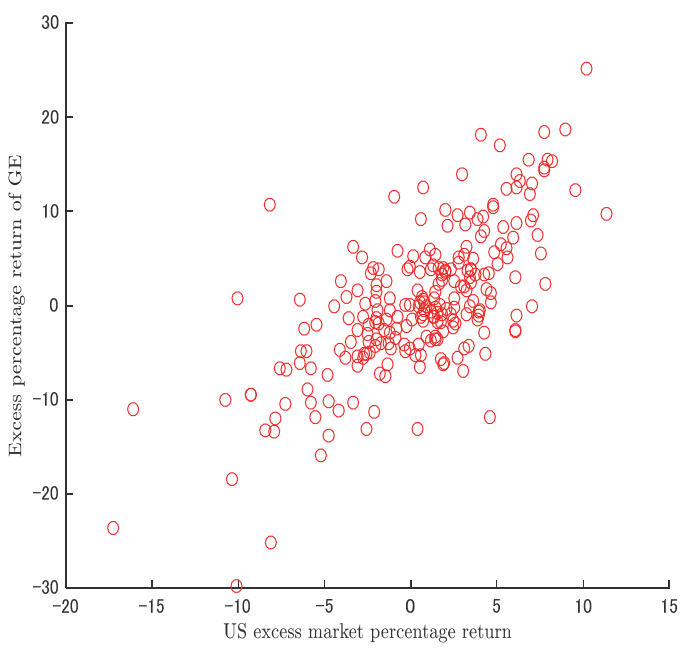

Figure 1. Excess stock percentage returns of the overall US equity market and ten US representative firms: For the period from June 1997 to January 2017

In Table 1, the descriptive statistics for the excess percentage returns of the overall US stock market and the above ten US firms. It is noted that the normality of 11 excess returns is all rejected by the Jarque-Bera tests. This means that during our analyzing period, all excess returns follow fat-tailed distributions. In particular, Bank of America and Amazon.com are rejected their normality by very large Jarque-Bera statistic values. Hence, it is interesting to note the estimation results as to linear and non-linear CAPMs with a particular focus on the cases of Bank of America and Amazon.com. Further, Figure 1 shows the scatter plots of the ten pairs of the US excess stock market returns and excess stock returns of the ten US firms.

\section{Models and Estimation Methods}

\subsection{OLS Estimation of the Standard Linear CAPM}

First, we estimate the following standard linear CAPM by applying the method of ordinary least squares (OLS).

$$
R_{i t}-R_{F t}=\alpha_{i}+\beta_{i}\left(R_{M t}-R_{F t}\right)+\tau_{i t}, \quad \tau_{i t} \sim N\left(0, \sigma_{i}^{2}\right) .
$$

In the above model (1), $R_{i t}-R_{F t}$ indicates one of the excess percentage returns of the ten US firms documented above. In 
addition, $R_{M t}-R_{F t}$ means the excess percentage return of the US equity market and $\beta_{i}$ denotes the CAPM beta value for stock $i$. In this model, the residual $\tau_{i t}$ is assumed to follow a normal distribution with the standard deviation, $\sigma_{i}$.

\subsection{Estimation of a Non-linear CAPM}

Next, we estimate the following non-linear CAPM (2) by the maximum likelihood (ML) method.

$$
R_{i t}-R_{F t}=\alpha_{i}+\beta_{i}\left(R_{M t}-R_{F t}\right)+\sigma_{i} \sqrt{\left(\omega_{i}-2\right) \varepsilon_{i t} / \omega_{i}} .
$$

In model (2), $\varepsilon_{i t}$ is the disturbance term of a Student's $t$ distribution; and $\omega_{i}$ is the parameter of degrees of freedom (DOF) for the distribution. Maximizing the following log likelihood function, we estimate this non-linear CAPM (2).

$$
\ln L_{t}\left(\theta_{i}\right)=\ln \left[\Gamma\left(\frac{\omega_{i}+1}{2}\right) / \sqrt{\pi \omega_{i}} \Gamma\left(\frac{\omega_{i}}{2}\right)\right]-\left(\omega_{i}+1 / 2\right) \ln \left[1+\left(\varepsilon_{i t}^{2} / \omega_{i}\right)\right]-\ln \sigma_{i}+\ln \sqrt{\omega_{i} /\left(\omega_{i}-2\right)} .
$$

In the above log likelihood function (3), $\Gamma(\cdot)$ denotes the gamma function.

\subsection{The Wald Test}

We further conduct the Wald test, and the null hypothesis is $\beta_{i}=1$, while the alternative hypothesis is $\beta_{i} \neq 1$. In this test, if $\beta_{i}=1$, the stock return of the firm $i$ behaves in a similar manner as the return of the overall US stock market.

\section{Empirical Results}

\subsection{Results of the Standard and Non-linear CAPMS}

As we already noted, it is highly important to pay attention to the differences of the estimation results for the linear and non-linear CAPMs by carefully focusing on the cases of Bank of America and Amazon.com. It is also interesting to pay attention to the results of the Wald tests by focusing on the cases of Bank of America and Amazon. First, in Table 2, the estimation results of the standard CAPM and our non-linear CAPM are shown; and this table firstly indicates that all linear CAPM models are successfully estimated by the OLS method. More concretely, as Table 2 shows, all beta values for the linear CAPM are statistically significantly derived. In addition, the results in this table secondly indicate that all non-linear CAPM models are also successfully estimated by the ML method. More specifically, as this table shows, all beta values for the non-linear CAPM are statistically significantly derived. For the non-linear CAPM, it is also shown that the parameters of DOF are statistically significantly estimated for all firms.

Focusing on the results of Bank of America and Amazon.com, the estimated linear CAPM beta value for Bank of America is 1.4114 , while the estimated non-linear CAPM beta value for the firm is 1.1380 . We note that these are clearly different in two models. Next, the estimated linear CAPM beta value for Amazon is 1.8980, while the estimated non-linear CAPM beta value for the firm is 1.5268 . We again note that these values are also clearly different in two models. We consider that these differences are because of the fat-tailed distributions of these two firms' excess stock returns. As we stated, our non-linear CAPMs are all well estimated, therefore, we consider that the values of ML betas are more reliable for Bank of America and Amazon.com. In fact, Table 2 also exhibits that the estimated DOF parameter for Amazon is the smallest value of 2.3566, and the estimated DOF parameter for Bank of America is the second smallest value of 2.8276 . We consider that these smaller parameter values very well capture the fat-tailed distributions of these two firms' stock returns via the ML estimations.

\subsection{Results of the Wald Tests}

Finally, we also explain the results of our Wald tests by again focusing on the cases of Bank of America and Amazon.com. First, Table 3 displays that the OLS estimator-based Wald test indicates that the return of Bank of America does not behave in a similar manner as the overall US stock market, while our ML estimator-based Wald test means the opposite result. It is noted that because Bank of America's stock return has a fatter-tailed distribution, for Bank of America, the result of the Wald test based on the ML estimators should be more reliable. Therefore, it is judged that Bank of America's stock return behaves as the overall US stock market for our analyzing sample period.

Next, as for Amazon, the two Wald test results based on the OLS and ML estimators are the same. As Table 3 shows, our two Wald tests both suggest that the stock return of Amazon does not behave in a similar manner as the overall US stock market. This is because for Amazon, the estimated beta values from the linear and non-linear CAPMs both take very large values of 1.8980 and 1.5268 , respectively; and these values are both far from one.

As we evidenced above, for fat-tailed stock returns, the Wald tests based on the non-linear CAPM estimators shall be more reliable than the Wald tests based on the linear CAPM estimators. In the case of Amazon, judged by the reliable high beta value of 1.5268 , which is from the non-linear CAPM estimators, it is naturally understood that the null-hypothesis of beta equals one is rejected for Amazon.com. 
Table 2. OLS estimation results of the linear CAPM and ML estimation results of the non-linear CAPM: The case of the US representative firms for the period from June 1997 to January 2017

\begin{tabular}{|c|c|c|c|c|c|c|}
\hline & \multicolumn{2}{|l|}{ Apple } & \multicolumn{2}{|c|}{ Bank of America } & \multicolumn{2}{|l|}{ Coca-Cola } \\
\hline & OLS & $\mathrm{ML}$ & OLS & ML & OLS & $\mathrm{ML}$ \\
\hline Alpha & $2.2383 * * *$ & $2.2117 * * *$ & -0.3309 & -0.3351 & -0.1678 & -0.0013 \\
\hline$t$-value & 3.0294 & 3.4216 & -0.5115 & -0.6922 & -0.4614 & -0.0040 \\
\hline$p$-value & 0.0014 & 0.0004 & 0.6953 & 0.7553 & 0.6775 & 0.5016 \\
\hline Beta & $1.3754 * * *$ & $1.3107 * * *$ & $1.4114 * * *$ & $1.1380 * * *$ & $0.4806^{* * *}$ & $0.4684 * * *$ \\
\hline$t$-value & 8.5159 & 8.7998 & 9.9827 & 9.2452 & 6.0440 & 5.8420 \\
\hline$p$-value & 0.0000 & 0.0000 & 0.0000 & 0.0000 & 0.0000 & 0.0000 \\
\hline Variance & & \multicolumn{2}{|l|}{$136.0264 * * *$} & $119.6948 * *$ & & $33.7874 * * *$ \\
\hline$t$-value & & \multicolumn{2}{|l|}{4.8126} & 2.3289 & & 4.6818 \\
\hline$p$-value & & \multicolumn{2}{|l|}{0.0000} & 0.0104 & & 0.0000 \\
\hline DOF & & \multicolumn{2}{|l|}{$4.0169 * * *$} & $2.8276^{* * *}$ & & $3.9772 * * *$ \\
\hline$t$-value & & \multicolumn{2}{|l|}{3.4099} & 4.5942 & & 3.3259 \\
\hline \multirow[t]{3}{*}{$p$-value } & & \multicolumn{2}{|l|}{0.0004} & 0.0000 & & 0.0005 \\
\hline & \multicolumn{2}{|l|}{ Microsoft } & \multicolumn{2}{|l|}{ Wal-Mart } & \multicolumn{2}{|c|}{ Amazon.com } \\
\hline & OLS & $\mathrm{ML}$ & OLS & ML & OLS & ML \\
\hline Alpha & 0.2171 & -0.2523 & 0.4040 & 0.1323 & $2.9783 * * *$ & $1.3162 * *$ \\
\hline$t$-value & 0.4372 & -0.6148 & 1.0438 & 0.3755 & 2.7725 & 1.8593 \\
\hline$p$-value & 0.3312 & 0.7303 & 0.1488 & 0.3538 & 0.0030 & 0.0321 \\
\hline Beta & $1.1918 * * *$ & $1.0874 * * *$ & $0.4775 * * *$ & $0.4714 * * *$ & $1.8980 * * *$ & $1.5268 * * *$ \\
\hline$t$-value & 10.9804 & 11.8152 & 5.6441 & 5.8523 & 8.0828 & 9.2472 \\
\hline$p$-value & 0.0000 & 0.0000 & 0.0000 & 0.0000 & 0.0000 & 0.0000 \\
\hline Variance & & $63.6008 * * *$ & & $36.8053 * * *$ & & 489.6108 \\
\hline$t$-value & & 3.8989 & & 5.6295 & & 0.9658 \\
\hline$p$-value & & 0.0001 & & 0.0000 & & 0.1676 \\
\hline DOF & & $3.4574 * * *$ & & $4.5422 * * *$ & & $2.3566 * * *$ \\
\hline$t$-value & & 4.1313 & & 3.1177 & & 4.8481 \\
\hline$p$-value & & 0.0000 & & 0.0010 & & 0.0000 \\
\hline & Exxon & & & JPMorgan & & \\
\hline & OLS & ML & & OLS & $\mathrm{M}$ & \\
\hline Alpha & 0.1283 & -0 . & & -0.0582 & & \\
\hline$t$-value & 0.4376 & -0 . & & -0.1276 & & \\
\hline$p$-value & 0.3311 & 0.5 & & 0.5507 & & \\
\hline Beta & $0.4954 * * *$ & 0.5 & & $1.4107 * * *$ & & $* *$ \\
\hline$t$-value & 7.7298 & 8.2 & & 14.1523 & & \\
\hline$p$-value & 0.0000 & 0.0 & & 0.0000 & & \\
\hline Variance & & 19. & $* * *$ & & & $* * *$ \\
\hline$t$-value & & 7.5 & & & & \\
\hline$p$-value & & 0.0 & & & & \\
\hline DOF & & 6.4 & & & & $* * *$ \\
\hline$t$-value & & 2.6 & & & & \\
\hline$p$-value & & 0.0 & & & & \\
\hline & Johnson \& & & & GE & & \\
\hline & OLS & MI & & OLS & $\mathrm{M}$ & \\
\hline Alpha & 0.3009 & 0.1 & & -0.3503 & & \\
\hline$t$-value & 0.9687 & 0.6 & & -0.9851 & & \\
\hline$p$-value & 0.1669 & 0.2 & & 0.8372 & & \\
\hline Beta & $0.4141 * * *$ & 0.4 & $* *$ & $1.1892 * * *$ & & $* *$ \\
\hline$t$-value & 6.0986 & 6.5 & & 15.2991 & & \\
\hline
\end{tabular}




\begin{tabular}{|c|c|c|c|c|}
\hline$p$-value & 0.0000 & 0.0000 & 0.0000 & 0.0000 \\
\hline Variance & & $22.7030 * * *$ & & $29.6737 * * *$ \\
\hline$t$-value & & 7.0060 & & 7.9206 \\
\hline$p$-value & & 0.0000 & & 0.0000 \\
\hline DOF & & $5.7181 * * *$ & & $7.2009 * *$ \\
\hline$t$-value & & 2.7930 & & 2.1961 \\
\hline$p$-value & & 0.0028 & & 0.0145 \\
\hline
\end{tabular}

Notes: In this table, $* * *$ and $* *$ mean the statistical significance of the estimates at the $1 \%$ and $5 \%$ levels, respectively. Moreover, OLS denotes the ordinary least squares, ML denotes the maximum likelihood, and DOF means the degrees of freedom parameter of the Student's $t$ distribution.

Table 3. Wald test results based on the OLS and ML estimators: The case of the US representative firms for the period from June 1997 to January 2017

\begin{tabular}{|c|c|c|c|c|c|c|}
\hline & \multicolumn{2}{|l|}{ Apple } & \multicolumn{2}{|c|}{ Bank of America } & \multicolumn{2}{|l|}{ Coca-Cola } \\
\hline & OLS & ML & OLS & ML & OLS & ML \\
\hline Wald & $5.4020 * *$ & $4.3508 * *$ & $8.4675 * * *$ & 1.2565 & $42.6802 * * *$ & $43.9520 * * *$ \\
\hline \multirow{3}{*}{$p$-value } & 0.0201 & 0.0370 & 0.0036 & 0.2623 & 0.0000 & 0.0000 \\
\hline & \multicolumn{2}{|l|}{ Microsoft } & \multicolumn{2}{|l|}{ Wal-Mart } & \multicolumn{2}{|l|}{ Amazon.com } \\
\hline & OLS & ML & OLS & ML & OLS & ML \\
\hline Wald & $3.1236^{*}$ & 0.9024 & $38.1313^{* * *}$ & $43.0569 * * *$ & $14.6242 * * *$ & $10.1805 * * *$ \\
\hline \multirow[t]{3}{*}{$p$-value } & 0.0772 & 0.3421 & 0.0000 & 0.0000 & 0.0001 & 0.0014 \\
\hline & \multicolumn{3}{|l|}{ Exxon } & \multicolumn{3}{|l|}{ JPMorgan } \\
\hline & OLS & \multicolumn{2}{|c|}{$\mathrm{ML}$} & OLS & \multicolumn{2}{|l|}{$\mathrm{ML}$} \\
\hline Wald & $61.9965 * * *$ & \multicolumn{2}{|c|}{$67.7271 * * *$} & $16.9769 * * *$ & \multicolumn{2}{|c|}{$19.9961 * * *$} \\
\hline \multirow[t]{3}{*}{$p$-value } & 0.0000 & & & 0.0000 & \multicolumn{2}{|c|}{0.0000} \\
\hline & \multicolumn{3}{|c|}{ Johnson \& Johnson } & GE & & \\
\hline & \multicolumn{2}{|l|}{ OLS } & ML & OLS & \multicolumn{2}{|c|}{$\mathrm{ML}$} \\
\hline Wald & \multirow{2}{*}{$\begin{array}{l}74.4863 * * * \\
0.0000\end{array}$} & \multicolumn{2}{|c|}{$61.1121 * * *$} & $5.9265 * *$ & \multicolumn{2}{|c|}{$5.6225^{* *}$} \\
\hline$p$-value & & \multicolumn{2}{|c|}{0.0000} & 0.0149 & \multicolumn{2}{|c|}{0.0177} \\
\hline
\end{tabular}

Notes: In this table, ***,**, and * represent the statistical significance of the statistic at the $1 \%, 5 \%$, and $10 \%$ levels, respectively. In addition, OLS denotes the ordinary least squares, ML denotes the maximum likelihood, and Wald means the Wald test statistic.

\section{Conclusions}

This study quantitatively explored the linear standard CAPM and a non-linear CAPM by using monthly stock returns of the US representative firms. Via the maximum likelihood estimation, we derived the following useful findings. (1) First, when the stock return distribution is fat-tailed, our non-linear CAPM application was highly effective. Because our non-linear CAPM parameters rather successfully captured the behavior of fat-tailed return distributions, the non-linear CAPM estimation derived more reliable beta value estimates than the standard linear CAPM. In this study, this effectiveness was suggested particularly by the cases of the stock returns of Bank of America and Amazon.com.

(2) Second, conducting the Wald tests based on the standard linear CAPM estimators and the non-linear CAPM estimators, we clarified that when the stock return distribution is fat-tailed, the Wald test result based on the non-linear CAPM estimators was more reliable than that based on the standard linear CAPM estimators. This was seen particularly in the case of Bank of America's stock return in this study. Furthermore, we also consider that even when the stock return is normally distributed, our non-linear CAPM estimator-based Wald test was also reliable since the model's degrees of freedom parameter can be adjusted for the normal distribution by taking larger values. The above interesting findings for academics and practice are the contributions of this article.

(3) Finally, we point out that the quantitative examinations demonstrated in this paper suggest the following important implications. Namely, both for fat-tailed and normally distributed stock returns, the application of our non-linear CAPM shall be highly effective. Likewise, as we stated above, it is considered that both for fat-tailed and normally distributed stock returns, the Wald test based on our non-linear CAPM estimators shall be also effective. Considering the clearness and usefulness of the research results demonstrated in this paper, extended investigations by applying similar approaches should be our future tasks. 


\section{Acknowledgements}

The author firstly thanks this journal for its kind repeated article invitation. In addition, the author greatly thanks James Young for his kind editorial assistance to this paper. Further, the author also thanks anonymous reviewers for their constructive and supportive comments on this paper. Moreover, the author also appreciates the Japan Society for the Promotion of Science Grant-in-Aid for Scientific Research and the Chuo University Personal Research Grant for their generous financial assistance to this research. Finally, I deeply thank all the Editors of this journal for their kind attention to my paper.

\section{References}

Agnello, R. (2016). Do U.S. paintings follow the CAPM? Findings disaggregated by subject, artist, and value of the work. Research in Economics, 70, 403-411. http://dx.doi.org/10.1016/j.rie.2016.06.002

Bai, Z., Wong, W. K., \& Zhang, B. (2010). Multivariate linear and nonlinear causality tests. Mathematics and Computers in Simulation, 81, 5-17. http://doi.org/10.1016/j.matcom.2010.06.008

Bai, Z., Li, H., Wong, W. K., \& Zhang, B. (2011). Multivariate causality tests with simulation and application. Statistics \& Probability Letters, 81, 1063-1071. http://doi.org/10.1016/j.spl.2011.02.031

Barberis, N., Greenwood, R., Jin, L., \& Shleifer, A. (2015). X-CAPM: An extrapolative capital asset pricing model. Journal of Financial Economics, 115, 1-24. http://dx.doi.org/10.1016/j.jfineco.2014.08.007

Fama, E. F., \& French, K. R. (1993). Common risk factors in the returns on stocks and bonds. Journal of Financial Economics, 33, 3-56. http://dx.doi.org/10.1016/0304-405X(93)90023-5

Guermat, C. (2014). Yes, the CAPM is testable. Journal of Banking \& Finance, 46, 31-42. http://dx.doi.org/10.1016/j.jbankfin.2014.05.001

Hur, S. K., \& Chung, C. Y. (2017). Revisiting CAPM betas in an incomplete market: Evidence from the Korean stock market. Finance Research Letters, forthcoming. http://dx.doi.org/10.1016/j.frl.2016.12.018

Lintner, J. (1965). The valuation of risk assets and the selection of risky investments in stock portfolios and capital budgets. Review of Economics and Statistics, 47, 13-37. http://dx.doi.org/10.2307/1924119

Mossin, J. (1966). Equilibrium in a capital asset market. Econometrica, 34, 768-783. http://dx.doi.org/10.2307/1910098

Sharpe, W. F. (1964). Capital asset prices: A theory of market equilibrium under conditions of risk. Journal of Finance, 19, 425-442. http://dx.doi.org/10.2307/2977928

Tiku, M. L., Wong, W. K., \& Bian, G. (1999). Estimating parameters in autoregressive models in non-normal situations: Symmetric innovations. Communications in Statistics - Theory and Methods, 28, 315-341. http://dx.doi.org/10.1080/03610929908832300

Tsai, H. J., Chen, M. C., \& Yang, C. Y. (2014). A time-varying perspective on the CAPM and downside betas. International Review of Economics \& Finance, 29, 440-454. http://dx.doi.org/10.1016/j.iref.2013.07.006

Tsuji, C. (2012a). Positive return premia in Japan. Quantitative Finance, 12, 345-367. http://dx.doi.org/10.1080/14697688.2010.541485

Tsuji, C. (2012b). Do industries contain predictive information for the Fama-French factors? Quantitative Finance, 12 , 969-991. http://dx.doi.org/10.1080/14697681003762271

\section{Copyrights}

Copyright for this article is retained by the author(s), with first publication rights granted to the journal.

This is an open-access article distributed under the terms and conditions of the Creative Commons Attribution license which permits unrestricted use, distribution, and reproduction in any medium, provided the original work is properly cited. 